\title{
Husk DUDS årsmøde 19. april 2013
}

\section{Foreløbigt program}

\author{
Urologisk Ultralyd \\ $\nabla$ \\ - 8.00-8.30 Registrering \\ - 8.30-8.45 Velkomst med introduktion \\ til Carlsberg \\ - 8.45-9.30 A Century of Prostate \\ Brachytherapy \\ Jesse Aronowitz, USA \\ - 9.30-9.50 UL af prostata \\ Nis Nørgaard, Herlev Hospital \\ - 9.50-10.10 MR af prostata \\ Vibeke Løgager, Herlev Hospital \\ - 10.10-10.45 KAFFE
}

\section{Pancreas}

$\nabla$

- 10.45-11.30 CEUS of pancreatic tumours Mirko D’Onofrio, Italy

- 11.30-12.00 CT \& MR af pancreas Eva Fallentin, Rigshospitalet

- 12.00-13.00 FROKOST
Nye Teknikker

$\nabla$

- 13.00-13.45 Elastography technique and potential applications Jeff Bamber, UK

- 13.45-14.15 Vektorflow - status og perspektiver

Kristoffer Lindskov Hansen, Rigshospitalet

- 14.15-14.45 KAFFE

\section{Korte Videnskabelige Foredrag}

$\nabla$

- 14.45-15.05 Elastografi-studier på fantomer Jonathan Carlsen, Rigshospitalet

- 15.05-15.25 Det laterale bånd af aponeurosis plantaris Michel Court-Payen, Gildhøj Privathospital

- 16.00-17.00 Guidet tur på Carlsberg turen foregår primært udendørs og strækker sig over ca. $1,5 \mathrm{~km}$.

- 17.00-18.00 Generalforsamling i DUDS
Sted: Carlsberg Museum \& Business Centre, Valby Langgade 1, 1799 København V

Kursusledelse: Charlotte Strandberg, Christina Kinnander og Michael Bachmann Nielsen.

Kursusgebyr: 1000 kr. Prisen inkluderer fortæring, herunder kaffe/te/vand og frugt i løbet af dagen og frokost samt rundvisningen.

Tilmelding til kursussekretær Linda Schumann snarest muligt på DUDS hjemmeside, www.duds.dk

Sidste frist for tilmelding er 15 . marts 2013.

Parkering/transport: Enghave Station og Valby Station er de nærmeste S-togs stationer (ca. 15 minutters gang). Alternativt kan man benytte bus 18 og 26. Der er mulighed for parkering i området, delvis som betalingsparkering. 